\title{
VERSOS (IN)VERSOS: \\ UMA ANÁLISE DA SÁTIRA LÍRICA NA POESIA DE PAULO LEMINSKI
}

\author{
Paulo Cesar Ferreira Soares (UVA) \\ Wellington Gomes de Sousa
}

Resumo: A análise aqui proposta visa ao apontamento de uma determinada regularidade da sátira na poética contemporânea de Paulo Leminski. Na literatura brasileira, o autor em questão representa uma espécie de liame entre a poesia livresca e a arte praticada no novo milênio, esta última sustentada pelos recursos de multimídia. Isso consiste numa peculiaridade do autor, visto que poucos poetas da chamada geração mimeógrafo ousaram preencher suas composições de sátiras líricas como o curitibano. Os poemas leminskianos nos despertam para uma reflexão indispensável acerca do lirismo instantâneo e corrosivo, envolvido de caráter satírico. Todo o caminho literário seguido pelo poeta em questão é um confronto satírico com os próprios sentimentos e/ou com a sensação de inutilidade romanesca diante da evasão cotidiana.

Palavras-chave: Literatura; Sátira; Lirismo; Poesia.

Abstract: The analysis proposed here aims the appointment of a certain regularity of satire in contemporary poetic of Paul Leminski. In Brazilian literature, this author is a kind of bond between the bookish poetry and art practiced in the new millennium, the latter supported by multimedia resources. This is a peculiarity of the author, as few poets of the called mimeograph generation dared fill their satires lyrical compositions like him. The Leminskianos poems awaken us to an indispensable reflection about the instantaneous and corrosive lyricism, involved by satirical character. All literary path followed by the poet is a satirical confrontation with his own feelings and / or with the novelistic futility sense against daily evasion.

Keywords: Literature; Satire; Lyricism; Poetry. 


\section{INTRODUÇÃO}

A poesia de Paulo Leminski vai muito além da classificação formal versus coloquial que a crítica literária conclama. Antes de ser o contraponto entre o erudito e o popular, o concretismo e a poesia marginal; a arte literária de Leminski tenta comunicar, em poucos versos, a inversão propositada do lirismo por meio da sátira de costumes e ideias. A sua produção literária vai de encontro à tendência crítica contemporânea que vê o passado, seja pela memória, seja pela história, como conflituoso e, por isso mesmo, fértil. "Ao presente restaria, o mais das vezes, a indiferença." (RESENDE, 2008, p.08).

Dessa forma, podemos dizer que a obra do poeta de Curitiba ainda representa uma pauta mal compreendida na contemporaneidade, mesmo sendo o todo das suas composições um jogo vocabular rápido e que, por isso, poderia ser mais perceptível para uma geração multimidiática. É o que se percebe nas palavras de Resende supracitadas, visto que a própria crítica literária, muitas vezes de caráter passadista, sinaliza para um valor atribuído à poética atual que paira no terreno da indiferença e do descaso.

Não obstante, é importante analisar o volume de poesias satíricas e ao mesmo tempo líricas de Paulo Leminski, de forma a suscitar a reflexão sobre o frequente diálogo com 
outras formas de expressão artística, o que faz da poesia leminskiana uma construção literária rica que envolve o leitor porque este se identifica com os dispositivos verbais que giram em torno de um lirismo às avessas, refletindo sentimentos muitas vezes ridicularizados pelo próprio indivíduo. Vale ressaltar a ideia de Compagnon (2012) ao afirmar que o contexto pertinente ao estudo de um texto literário não é o oriundo desse texto, mas a sociedade que faz dele um uso literário, separando-o de seu contexto de origem. Por isso, em nossa análise, estaremos diante de um contexto contemporâneo, de uma poesia que brota da problemática social em meados dos anos 80 .

A base literária do poeta curitibano é existencial, repleta de peculiaridades que refletem os anseios de uma nova estética, o que nos permite tratar do vínculo entre poesia e cotidiano. Ao escolher a sátira para abordar temas líricos, Leminski aponta para uma filosofia de vida e/ou para um romantismo desgastado ao longo da história.

No Brasil, poucos poetas conseguiram sintonizar sátira e lirismo economizando no discurso, como é o caso a ser pesquisado neste artigo. Na verdade, até mesmo essa diversificação poética é pouco presente no nosso contingente literário. A junção dessas nuances em um só poema, como 
faz o poeta curitibano, que encadeia sátira e lirismo, promovendo uma espécie de fusionismo idiossincrático em suas construções poéticas, é algo que lhe é muito particular.

O espaço entre literatura e realidade histórica, na obra de Leminski, é preenchido por uma sátira em muitos casos corrosiva. Um estudo a ser inserido na nossa pesquisa vem da Análise do Discurso, mais precisamente da teoria de Michel Pêcheux. Assim, a língua e a literatura não se distanciam da realidade. O discurso poético do autor em estudo é astuto, mesclando leveza formal e objetividade temática.

Em Leminski, o impacto poético de seus versos rápidos e a palavra em seu estado puro tornam a poesia satírica com alguma dose de lirismo - mais consistente e penetrante no que diz respeito ao público leitor. Vale ressaltar, também, que é perceptível a sobreposição da sátira em relação ao lirismo de sua poética, algo que será objeto de nossa análise. POESIA MARGINAL: TEMPO E ESPAÇOS CONTEMPORÂNEOS

deixando branca a página para que a paisagem passe e deixe tudo claro à sua passagem Marginal, escrever na entrelinha, sem nunca saber direito quem veio primeiro, o ovo ou a galinha. Paulo Leminski 
$\mathrm{Na}$ literatura brasileira, o período romântico engloba grande parte das pesquisas acadêmicas. É visível a atenção, a ênfase que se dá nas características e conceitos da poesia dessa época. Para Coutinho (2004), essa fase da literatura nacional marca definitivamente a proposta artística do Brasil. Certamente, por conta da importância inerente à escola romântica, é que há o debruçar-se acadêmico sobre esse movimento que suscitou, em tese, a 'independência' literária do Brasil, pois a partir dela tivemos o momento "correspondente ao período de implantação e definição do novo credo cultural" (MOISÉS, 2005, p.117).

Vale dizer que cada movimento desses - até o Modernismo - tinha características específicas e, geralmente, buscava contemplar anseios poéticos que despertassem o gosto de seus leitores. Consistia, o mais das vezes, numa construção poética da elite e para a elite. O gosto pessoal do autor, portanto, era, muitas vezes, fazer valer o gosto do leitor burguês. Com o advento do Modernismo, a partir da Semana de 22, surgem, também, lampejos de poesia descompromissada com o rigor formal, principalmente do Parnasianismo, e que pleiteia novos horizontes poéticos na Literatura Brasileira.

Com o surgimento das condições basilares para uma nova poética, o chamado Pós-modernismo trouxe um vácuo 
classificatório a ser preenchido pelos poetas marginais. "Dentro de nós há identidades contraditórias, empurrando em diferentes direções, de tal modo que nossas identificações estão sendo continuamente deslocadas" (HALL, 2011, p.13). Valendo-nos das palavras de Hall, podemos dizer que a construção literária seja em prosa ou poesia, não segue, a partir da contemporaneidade, um único caminho literário; tampouco é direcionada a um público leitor elitizado como outrora. Diante disso, é importante ressaltar que a

$$
\begin{aligned}
& \text { poesia que floresceu nos anos } 70 \text { é } \\
& \text { inquieta, anárquica. Não se filia a } \\
& \text { nenhuma estética literária em particular, } \\
& \text { embora se possam ver nela traços de } \\
& \text { algumas vanguardas que a precederam, } \\
& \text { tais como do concretismo dos anos } 50 \text { e } \\
& 60 \text { ou do poema-processo (CAMPEDELLI, } \\
& \text { 1995, p.27). }
\end{aligned}
$$

As nuances literárias passam a ser diversificadas e antes disso surge, por exemplo, a partir da década de 60, os movimentos literários ligados às vanguardas universais. Podemos destacar aqui o concretismo ${ }^{1}$ e suas especificidades estruturalizantes, que causou um impacto significativo no cenário literário brasileiro. Para Coutinho (2004), o momento de eclosão do concretismo foi caracterizado por grande

\footnotetext{
1 Movimento de vanguarda, da década de 50. No Brasil foi idealizado por Décio Pignatari e os irmãos Haroldo e Augusto de Campos. O concretismo atribuía ao poema, a predominância visual, em consequência disso, o fim do verso.
} 
polêmica nacional, que marca o período de 1956/60. Toda essa polêmica, citada por Coutinho, deve-se, certamente, ao fato da 'radicalização poética' da poesia concreta que se opõe à poesia intimista e retoma atitudes peculiares à geração de 22, como nos diz Bosi:

No contexto da poesia brasileira, o Concretismo afirmou-se como antítese à vertente intimista e estetizante dos anos 40 e repropôs temas, formas e, não raro, atitudes peculiares ao Modernismo de 22 em sua fase mais polêmica e mais aderente às vanguardas europeias. [...] o Concretismo toma a sério, e de modo radical, a definição de arte como techné, isto é, como atividade produtora. De onde, o primeiro corolário: o poema é identificado como objeto de linguagem [...] (2006, p.476 - grifo nosso).

Embora Paulo Leminski tenha sido um dos poetas que se embebeu na fonte concretista em seu fazer literário, é notório que há uma preocupação maior, em sua poesia, com o conteúdo a ser trabalhado do que com a forma na qual este aparecerá na superfície poética, isto é, a disposição gráfica do verso consiste apenas em um dos artifícios utilizados por ele para expressar a sua sátira lírica. Em suma, Leminski é ícone "de uma poesia de caráter experimental, não raro declaradamente rebelde" (MOISÉS, 2005, p.529). Dessa forma, o poeta curitibano dá ênfase à sátira a despeito do 
texto romântico, fazendo-se valer da forma vanguardista em contradição aos anseios líricos da sociedade.

Na esteira da geração de 70, ou seja, dos poetas marginais, a poesia de Paulo Leminski ganha embasamento teórico. Embasamento este de cunho literário, linguístico, discursivo e até certo ponto político. Mas, ele soube filtrar com maestria as concepções do grupo 'mimeógrafo' e assim adaptou a expressão artística marginal aos preceitos de gerações literárias livrescas. "São múltiplos tons e temas e, sobretudo, múltiplas convicções sobre o que é literatura [...] o pós-modernismo passa a operar num campo de tensão entre tradição e inovação, conservação e renovação" (RESENDE, 2008, p.18).

Com isso, deve-se levar em consideração a relação que há entre literatura e realidade, visto que o fazer literário contempla - ou reflete - um dado contexto sócio-histórico e esse contexto dualista no campo da literatura, mencionado pelo autor supracitado, contribui para a concepção também dualista da sátira lírica de Leminski, assim como para toda a elaboração artística da geração "mimeógrafo". Tendo como pano de fundo os 'negros verdes anos 70', a poesia marginal dá uma guinada na construção literária brasileira,

\footnotetext{
2 Expressão cunhada por Heloísa Buarque de Holanda para mostrar que, de fato, a década de 70 começa, no Brasil, a 13 de dezembro de 1968, quando foi editado o Ato Institucional $n^{\circ} 5$, anunciador de um tempo nebuloso, com fortes vetos que abalavam a estabilidade meteorológica de nossa história política e de nossa cultura. (HOLANDA \& PEREIRA Apud CAMPEDELLI, 1995, P.11).
} 
principalmente concebendo uma poesia que busca preencher "um vazio cultural que teria dado o tom de época na área das artes e da literatura" (HOLANDA \& PEREIRA Apud CAMPEDELLI, 1995, p.11). Por isso,

a poesia que os jovens poetas apresentaram distribuída de mão em mão, impressa em mimeógrafo, declamada em bate-papos de botecos, foi extremamente atenta às crises político-existenciais da história de seu tempo e redimensionou um conceito démodé de poeta, visto como alguém recolhido, sofrido e abatido (CAMPEDELLI, 1995, p.11).

A partir desse 'novo' paradigma artístico, a literatura brasileira, sob a ótica dos poemas de Leminski, ganha uma ambientação própria e, como afirma Resende (2008), começa a mobilizar-se na angústia do leitor pós-moderno, que anseia por uma nova expressão artística que não mais endosse o sentimentalismo, o artificialismo poético e, sim, se encarregue da sátira aos costumes, da crítica ao estado passional das pessoas.

O poema de Leminski que serve de epígrafe para esta seção, nos sinaliza a angústia citada por Resende em suas palavras. $\mathrm{O}$ samurai malandro ${ }^{3}$ traz à tona, no último verso, uma situação GÓES, Fred; MARTINS, Álvaro. Melhores poemas de Paulo Leminski. 7 ed. São Paulo: Gaia, 2006. 
que desde sempre é passível de questionamento ao passo que deixa claro o caráter inerte da sociedade, bem como faz uma crítica à submissão em relação ao fazer poético.

Os tempos atuais são, sabe-se, sombrios. Em ritmo acelerado, agonizam sociedades, agonizam homens. "O discurso globalizador, por vezes banalizado pela insistência, confronta-se cotidianamente com situações de impasse" (PINTO, 2004, p.72). Nessa afirmação, podemos identificar a temática urbana da poesia contemporânea. $E$ a satirização foi a estratégia escolhida por vários poetas para protestar contra esse processo desigual e caótico, dentre esses autores, o que mais se utilizou da sátira foi Paulo Leminski.

E é nesse cenário profícuo que surge a figura de Paulo Leminski. Poeta nascido em Curitiba, em 1944. Também foi romancista, tradutor, compositor e ensaísta. Seu livro de romance mais simbólico é Catatau. Estreou na poesia em 1976 e suas obras mais significativas foram: Caprichos e relaxos (1983), Distraídos venceremos (1987), La vie em close (1991) e O ex-estranho (1996). O poeta faleceu aos 45 anos em 1989. Sendo que as últimas obras foram editadas e publicadas por sua esposa Alice Ruiz. 


\section{LEMINSKI E AS DUALIDADES DE SUA POESIA}

Nesse capítulo, nos detemos em comentar o dualismo do processo de construção da poética de Leminski. "A ideia de que uma obra literária é uma forma concreta, que expressa um conteúdo abstrato, levou a Teoria da Literatura a decompor a obra em dois elementos fundamentais: forma e conteúdo [...]" (AMORA, 2006, p.57-58). Podemos nos valer dessa abordagem teórica da literatura para analisar a feitura literária do poeta marginal Leminski que promove a junção desses planos de expressão e de conteúdo, respectivamente, de forma diferenciada daquilo que se vê, o mais das vezes, na poesia brasileira.

Levando em consideração os desdobramentos da vanguarda concretista, Bosi (2006) afirma que se buscou uma construção poética que transpusesse as barreiras internas do verso; algo que pudesse ir além do aproveitamento gráfico das palavras dispostas no papel, como ocorria, por exemplo, no Concretismo na década de 1950. Em outras palavras, reclamava-se a criação de um lirismo, tal e qual Manuel Bandeira reivindicava em Poética, que fosse libertação, até mesmo para ser sarcástico, como é recorrente na poesia de Paulo Leminski, autor cujo lirismo pode ser percebido como inovador em relação ao que aparecia até então em nosso 
panteão poético. No poema que segue podemos visualizar, por exemplo, a distorção do sentimentalismo romântico em prol do sarcasmo poético:

um dia desses quero ser
um grande poeta inglês
do século passado
dizer
ó céu ó mar ó clã ó destino
lutar na índia em 1866
e sumir num naufrágio clandestino.

No poema percebe-se que, apesar da presença de características românticas como o escapismo, a essência poética ironiza o sentimentalismo impregnado na estética romântica. De maneira objetiva, o eu lírico mostra ao leitor um flash satírico que aparece em detrimento ao caráter jocoso do lirismo romântico presente na fase ultrarromântica. Por isso, podemos dizer que o lirismo leminskiano, que escapa de emoções fatigadas, do rigor formal que a crítica, muitas vezes, cobra da poesia brasileira, é um ícone dessa transformação poética que teve grande contribuição da geração marginal da qual ele fazia parte.

Para Pêcheux (2012) há uma noção de materialidade discursiva enquanto nível de existência sócio histórica, que não é nem a língua, nem a literatura [...] mas que remete 
às condições verbais de existência dos objetos (científicos, estéticos e ideológicos). Nos versos leminskianos, podemos perceber o caráter dicotômico dessa materialidade discursiva em relação à verbalização dos objetos como ocorre em Iceberg:

\author{
Uma poesia ártica, \\ claro, é isso que eu desejo. \\ Uma prática pálida, \\ três versos de gelo. \\ Uma frase superfície \\ onde vida-frase alguma \\ não seja mais possível. \\ Frase, não. Nenhuma. \\ Uma lira nula, \\ reduzida ao puro mínimo, \\ um piscar do espírito, \\ a única coisa única. \\ Mas falo. E, ao falar, provoco \\ nuvens de equívocos \\ (ou enxame de monólogos?). \\ Sim, inverno, estamos vivos.
}

Artista versátil, Leminski fez-se valer de vários recursos para a sua construção poética, entre os quais usou dos artifícios semióticos da língua com o intuito de promover a reflexão sobre dadas realidades, mediante a transformação 
verbal que se dá na sua inventividade poética. Dessa forma, é comum a fragmentação do signo linguístico na obra leminskiana, o que a torna breve e enigmática; capaz de suscitar impressões que podem passear por dualidades diversas que vão além da captação da relação entre significado e significante, pois sua marca constante é a sátira poética, o que deixa o lirismo em segundo plano.

Apesar de ser poeta marginal, Leminski herdou recursos da vanguarda concretista como jogos sonoros, uso construtivo dos espaços brancos, trocadilhos além de outras ferramentas do Concretismo, o que, contudo, não tira a sua essência poética sátira-lírica em seu fazer literário. Assim como outros poetas de seu tempo, sua poesia é concebida como

atitude de desafogo, mais do que como realização formal convincente, a nova poética exprime-se na lírica dita 'marginal', abertamente anárquica, satírica, paródica, de cadências coloquiais e, só aparentemente, antiliterárias. (BOSI, 2006, p.487 - grifo nosso)

É importante frisar que não há negação ao lirismo, mas uma nova perspectiva lírica na poesia de Leminski, regada por uma sátira, que Ihe é peculiar e inovadora. Há, na verdade, um conflito do eu real com o pseudo eu lírico, mas ambos envolvem o leitor para que este encontre, no jogo de 
palavras, uma ou outra situação favorável para o romantismo, ou para as adversidades das relações interpessoais. Levando em consideração a relação entre literatura e realidade, podemos afirmar que os textos evocam uma inadequação amorosa, uma caricatura moderna das situações passionais.

Embora fosse poeta - assim como compositor, ensaísta, professor, etc. - multifacetado, Leminski teve sempre como marca registrada do seu fazer literário a sátira, cujo objetivo era debochar de situações sentimentais do eu, bem como ironizar a visão da sociedade em relação às questões peculiares a um lirismo quase sempre paradigmático, cultuado em outros momentos da literatura brasileira.

Portanto, o viés lírico da poesia de Leminski é decorado com uma sátira incisiva que direciona a análise de seus versos para o entendimento de que ele "imprimiu sua marca personalíssima a tudo que escreveu. Uma marca, sobretudo dinâmica, uma dicção própria, certo modo especial de dizer que vai do lirismo reflexivo à ironia e ao cinismo" (GUIMARÃES, 1989, p.90).

\section{CONSIDERAÇÕES FINAIS}

A poesia de Leminski nos oferece um viés bastante extenso para análise de sua sátira em detrimento ao lirismo convencional, via de regra incutido na poesia brasileira. 
A miscelânea de fatores que constituem o envoltório poético leminskiano torna complexa a tarefa de análise da poesia do autor curitibano. Góes \& Marin (2006) pontuam essa complexidade acerca da obra do samurai malandro, relatando que o estudo de qualquer aspecto sobre a construção literária do poeta marginal é como andar num labirinto sem limites.

Por isso, nosso propósito foi apenas tecer uma análise acerca da perspectiva satírica da obra de Leminski que se sobrepõe ao aspecto lírico de sua poesia. É perceptível essa relação dicotômica impregnada em seu fazer poético relacionado ao caráter dualístico de sua personalidade. Podemos dizer que a sátira leminskiana aparece como ferramenta de combate ao seu próprio lirismo, estabelecendo um conflito do eu com as questões cotidianas nas quais não cabe sentimentalismo.

Parece-nos que aquelas duas questões (sátira versus lirismo) apresentam-se como recorrentes na poética de Leminski. Ambas expressam a urgência de um realismo metafórico e incompleto quanto aos fatores românticos. Em nossa pesquisa, a contemporaneidade é pano de fundo para a captação desse realismo incondicional. Não há barreiras estilísticas para que o poeta em questão transcenda os 
códigos da poesia. Ele, em sua dualidade tão característica, desorganiza conceitos clássicos acerca do lirismo, dos aspectos romanescos atribuídos, durante toda a história da literatura brasileira, à poesia.

O que vimos nesse estudo foram hipóteses que contextualizam, todavia, desvinculam o lirismo de escolas literárias pretéritas dos preceitos sociais modernos. No plano da sátira, encontramos o liame entre poesia e lirismo. Tudo isso, dentro da obra de Paulo Leminski. A crítica literária atual talvez não tenha se atentado para era sátira frequente, já que os estudos sobre o autor supracitado movem-se, geralmente, em torno da forma (estrutura) dos seus poemas.

Coutinho (2004) fala de um pleno reino da liberdade e da pesquisa estética, como se cada poeta estabelecesse as suas próprias regras. E no caso de Leminski, não há uma predisposição em "seguir" o que foi ditado pelo cânone literário. Nem na forma, e na questão específica, nem no conteúdo dessa poesia. Esperamos que tal estudo embase futuras pesquisas acerca dessa nova versão e/ou Inversão lírico-satírica nos versos de Paulo Leminski. 


\section{REFERÊNCIAS}

AMORA, Antônio Soares (2006). Introdução à teoria da literatura. 13.ed. São Paulo: Cultrix.

BOSI, Alfredo (2006). História concisa da literatura brasileira. 43.ed. São Paulo: Cultrix.

CAMPEDELLI, Samira Youssef (1995). Poesia marginal dos anos 70. São Paulo: Scipione.

COMPAGNON, Antoine (2010). O demônio da teoria: literatura e senso comum. 2.ed. Belo Horizonte: Editora UFMG.

COUTINHO, Afrânio (2004). A literatura no Brasil. 7.ed. São Paulo: Global. GUIMARÃES, Denise Azevedo Duarte (1989). A poesia de Paulo Leminski: capricho, irreverência e paixão. Curitiba: UFPR. p.85-93.

HALL, Stuart (2011). A identidade cultural na pós-modernidade. (Reimp). 11.ed. Rio de Janeiro: DP\&A.

GÓES, Fred; MARTINS, Álvaro (2006). Paulo Leminski - Melhores Poemas. 7.ed. São Paulo: Gaia.

LEMINSKI, Paulo (2013). Toda Poesia. 1.ed. São Paulo: Companhia das Letras.

MOISÉS, Massaud (2005). A literatura brasileira através dos textos. 25.ed. São Paulo: Cultrix.

ORLANDI, Eni Puccinelli (2012). Análise do Discurso: Michel Pêcheux. Textos selecionados. 3.ed. Campinas: Pontes Editores.

PINTO, Júlio Pimentel (2004). A leitura e seus lugares. São Paulo: Estação Liberdade.

RESENDE, Beatriz (2008). Contemporâneos: expressões da literatura brasileira no século XXI. Rio de Janeiro: Casa da palavra Biblioteca Nacional.

Paulo Cesar Ferreira Soares - Mestrando em Ensino (PPGE) da UERN Universidade Estadual do Rio Grande do Norte (Campus Pau dos Ferros) 2015. Especialização em língua portuguesa e arte da educação(URCA/ CE). Graduação em Letras, com habilitação em língua portuguesa e suas 
respectivas literaturas pela Universidade Regional do Cariri (URCA). Desenvolveu estudos de pós-graduação na referente Universidade com foco na literatura de cordel em sala de aula. Professor efetivo (MAG) do estado do Ceará desde 2006. Atua na área de linguagens e códigos. Professor substituto da Universidade Vale do Acaraú (20052013) ministrou disciplinas de língua portuguesa, literatura brasileira, literatura cearense e história da língua portuguesa. Exerceu a função de coordenador pedagógico (2010-2012) Participou - como orientador - da elaboração da Proposta Curricular de Língua Portuguesa para o Ensino Fundamental I do estado do Ceará (2013). Atualmente é formador do PAIC (Programa de Alfabetização na Idade Certa) exercendo suas atividades formativas com professores de 12 (doze) municípios da jurisdição da CREDE 18. Enquanto formador atuou nos cinco Eixos do Programa: Alfabetização, gestão, avaliações externas, Educação Infantil e Eixo de Literatura. Em 2014, coordenou o grupo de estudo Café com PAIC (rodas de conversas sobre políticas públicas na alfabetização de crianças). 